\title{
Composition of motivation profiles at work using latent analysis: theory and evidence
}

This article was published in the following Dove Press journal: Psychology Research and Behavior Management

\author{
Chun-Xiao Chen' \\ Jian Zhang' \\ Faheem Gul Gilal ${ }^{2}$ \\ 'Department of Business Administration, \\ Donlinks School of Economics and \\ Management, University of Science and \\ Technology Beijing, Beijing 100083, \\ People's Republic of China; ${ }^{2}$ Department \\ of Business Administration, Sukkur IBA \\ University, Sukkur, Sindh, Pakistan
}

Purpose: Drawing from self-determination theory, the present study aims to identify the structures and functions of work motivation profiles by using a person-centered approach and to explore the relationships between work motivations and different work performances in the workplace.

Materials and methods: The participants in this research are from different provinces in China, such as Beijing, Tianjin, Shandong, and Hebei. The participants work in state-owned enterprises, private enterprises, foreign-funded enterprises, and public institutions. We contacted the head of the human resources department of the company where the employee was located, and then the human resources supervisor sent the questionnaire to the relevant employees for data collection. In Study 1, we obtained a total of 842 valid questionnaires. In Study 2, employee work performance was assessed by immediate supervisors, and we obtained a total of 630 valid matched data. This study identified the structure and function of work motivation profiles using a person-centered approach, ie, latent profile analysis. The analysis of variance approach was used to explore the relationship between work motivations and different work performances in the workplace.

Results: Using latent profile analysis, we found 5 work motivation profiles: dominant, highmidrange, low-midrange, intrinsic motivation-minor and intrinsic motivation-dominant. The five different profiles varied in the level (quantitative differences: dominant, high-midrange, and low-midrange) and shape (qualitative differences: intrinsic motivation-minor and intrinsic motivation-dominant) of the profile indicators. We found that these profiles differentially predicted employee performance. Our results reveal new insights into work motivations and how different work motivation profiles affect work performance.

Conclusion: We employed a new perspective to better understand the relations between motivations and work performance under the framework of self-determination theory. We were able to demonstrate that (1) different motivation strategies at work do consistently exist and (2) latent profile membership differentiates employee work performance. Our results show that high performance can be exhibited when an employee's motivation is the dominant type. High-dominant employees with high intrinsic motivation and low extrinsic motivation exhibit worse task performance. The results of this research show that a person-centered approach can better clarify the complexity of the process regarding how work motivations interact within an employee. The major theoretical contribution of this research is the use of latent profile analysis (LPA) to demonstrate five different subpopulations that can exhibit different combinations of work motivations in the emerging market of China. Second, our results show that identified regulation is important in predicting work performance. Third, we advanced the self-determination theory (SDT) research by exploring the relations between different motivation profiles and work performance.

Keywords: work motivation, work performance, latent profile analysis, person-centered approach, emerging economy, self-determination theory
Correspondence: Jian Zhang

Donlinks School of Economics and Management, University of Science and Technology Beijing, 30 Xueyuan Road, Haidian District, Beijing 100083, People's Republic of China

Tel +86 I 362 I3। 3495

Email zhangj67@manage.ustb.edu.cn 


\section{Introduction}

Campbell's definition of work performance is widely recognized, and it refers to the "behaviors or actions that are relevant to the goals of the organization". 1 Employee work performance is a popular issue in management literature, which has attracted considerable attention in recent years. Many researchers have focused on this topic, and many organizational management studies see it as the dependent variable. ${ }^{2}$ Work motivation is a

set of energetic forces that originate both within as well as beyond an individual's being to initiate work-related behaviors and to determine their form, direction, intensity, and duration. $^{3}$

Existing literature on job performance shows that employee motivation is one of the key factors promoting job performance. ${ }^{3,4}$ Academic research has shown the different effects of work motivation on different types of work performance. ${ }^{5}$

The relationship between work motivations and work performance has been evaluated in the extant literature, and researchers have reported different conclusions. Most of the extant literature has described the motivations as extrinsic or intrinsic, ${ }^{4}$ and literature about intrinsic motivations indicates that these motivations can improve work performance. ${ }^{6,7}$ However, the extant literature has suggested that sometimes an individual's behaviors cannot be explained by intrinsic motivations. ${ }^{8}$ For example, employees may be devoted to their work because they feel responsible for their work or because they understand the importance of their work activities, not because they are interested in it. ${ }^{4}$ According to the extant literature about extrinsic motivations, Rogstadius found that extrinsic motivations could not improve employees' work performance. However, Mekler performed experimental research and found that extrinsic motivations can promote work performance. ${ }^{9}$ The different conclusions between work motivations and work performance in the extant literature cannot provide effective suggestions that managers can use to improve employee work performance through their motivations.

There are two main reasons for these different conclusions. First, the division of extrinsic motivations is too general in the extant literature. Self-determination theory (SDT) has proposed a continuum model, which differs from the previous distinction of extrinsic and intrinsic motivation. ${ }^{10,11}$ In the continuum model, extrinsic motivation is divided into different forms of motivation regulations, such as external, introjected and identified motivations. ${ }^{12}$ Therefore, the multidimensional conceptualization of the motivation types provides a more nuanced method of exploring the effect of motivational types on work performance. Second, the previous method of examining the relationship between work motivation and work performance is based on a variable-centered approach, which does not take into account the way that individuals can be motivated by the association of different motivations with one another. Although variable-centered approaches have demonstrated many insights into the relationship between work motivation and other variables, person-centered approaches (eg, latent profile analysis) have the potential to extend work motivations by identifying how different profiles are differentially linked to antecedents and outcomes. ${ }^{13,14}$

Following the self-determination theory perspective, the current research aims to identify the structures and functions of work motivation profiles by introducing a person-centered paradigm. In particular, this study aims to contribute to the present body of knowledge in two distinct ways. First, the present study expands on the literature to study motivational profiles in the emerging market of China. Most previous studies have conducted a latent profile analysis for motivation in developed countries. Specifically, our study broadens the literature by using latent profile analysis to investigate work motivations. Second, we identified different work motivation profiles and found that different profiles differentially predicted work performance. Our findings reveal new insights into work motivations and suggest that each employee may use different combinations of work motivations to motivate their work performance. Furthermore, the results may also provide suggestions to management regarding the distinct combinations of work motivations.

\section{Theory and hypotheses}

\section{Motivation constructions from SDT}

Most of the extant literature has described motivations as either intrinsic motivations or extrinsic motivations. ${ }^{4}$ Following these theories, extrinsic behaviors are directed by an external mechanism, for example, reputation or money. Although intrinsic behaviors are guided by a person's interests, ${ }^{7}$ studies about motivation continue to be pursued. ${ }^{15}$ Existing studies have suggested that a person's behavior cannot be account for by intrinsic or extrinsic 
incentives. ${ }^{8}$ The extant literature ignores the disadvantages of the division of work motivation. For example, some employees are responsible, and they may be busy at work simply because they identify with their work, not because they are interested in their work.

Deci and Ryan proposed SDT and thought that different motivations could coexist. An important aspect of SDT is that it provides a new perspective for work motivations and has become a new positive theory. Furthermore, SDT purports that extrinsic motivations are different in the degree that they are internalized. ${ }^{16}$ According to SDT, extrinsic regulations have three different types: external regulation introjected regulation and identified regulation. ${ }^{17}$ External regulation is located at the low end of the continuum, and it refers to execute a task in order to get rewards or avoid punishment. ${ }^{18}$ Introjected regulation is an internal regulation, although it is not accepted as personal regulation. Rather, introjected regulation refers to the performance of a task because the person wants to maintain their self-worth or avoid guilt. ${ }^{19}$ Identified regulation is autonomously regulated. It refers to engagement in a task because a person identifies with the activity. ${ }^{20}$ In summation, SDT offers a creative conceptualization of the internalization of motivations and a multidimensional perspective of motivation. ${ }^{10,16}$

\section{Relationship between work motivations and work performance}

Work performance is the most typical variable in work organizational research. Work performance refers to the behaviors or actions that are relevant to the goals of organization. ${ }^{1}$ According to the literature, the structure of work performance has generated dozens of studies. ${ }^{21-25}$ There are four dimensions of work performance: interpersonal performance, adaptive performance, dedicative performance, and task performance. ${ }^{2}$ Interpersonal performance refers to the relationship between facilitation and collaboration; adaptive performance relates to adaptive behavior in an organization. When the conditions change, the person can adapt to the environment well; dedicative performance refers to the degree that a person copes with the difficulties. Task performance relates to individual ability and work knowledge, and it refers to how an individual's work contributes to the organization's technical core. ${ }^{26,27}$

SDT suggests that an intrinsic motivation refers to activities for which the motivation promotes the behavior itself. ${ }^{28}$ When intrinsically motivated, employees experience interest and enjoyment in the work ${ }^{29}$ and tend to display high-quality performance. ${ }^{4,30}$ In a meta-analysis, Nicklin suggested that intrinsic motivations are positively related to work performance, especially the quality of the work performed. ${ }^{31}$ For the relationship between extrinsic motivations and work performance, previous research has not resulted in consistent conclusions. External incentives can promote positive outcomes because it can deliver the message that a person is capable. ${ }^{32}$ External incentives are also important to improve employee's performance, persistence, and productivity. ${ }^{33}$ However, some studies think that extrinsic motivations may diminish work performance. The more extrinsic motivations that employees have, the more job burnout that tends to occur, ${ }^{34}$ which may reduce employees' work engagement and work performance. Previous studies about the impact of work motivations from the SDT perspective still focus on the variable-centered approach by studying how different motivations independently or additively affect different performances. As such, using LPA, we tried to find the structure and the function of distinct work motivation profiles that comprise intrinsic motivations, identified regulations, introjected motivations and extrinsic motivations and their potential for differential functional implications. ${ }^{35}$

\section{Person-centered approach—latent profile analysis}

Latent profile analysis (LPA) is used to construct a typology or clustering based on a set of observed variables. That is, it classifies observational units into a set of latent classes. In related psychology research, the aim of using the latent categorical approach would be to simply the latent classes by investigating their association with external variables and explore the relationships between that variable and other observed auxiliary variables.

LPA can distinct subpopulations that are different in the quality (shape) and quantity (level). ${ }^{36}$ According to Marsh, quantitative difference means profiles differ absolutely in the level of indicators. ${ }^{36}$ In this research, individuals in the profile have high intrinsic motivations, identified regulations, introjected regulations and extrinsic motivations and the other profile contains the person that is low in intrinsic motivations, identified regulations, introjected regulations and extrinsic motivations. The qualitative difference means profiles vary in profile indicators relatively. In the current research, that means the person in the profile that has high intrinsic motivations, identified regulations and low deep introjected regulations and extrinsic motivations, whereas another profile has 
moderate intrinsic motivations, identified regulations, introjected regulations and extrinsic motivations.

In the work domain, the academic research by Van den Brock employed cluster analysis to divide the employees' motivation into four types: "high autonomous/low controlled motivation" (HA/LC), "high autonomous/high controlled motivation" (HA/HC), "low autonomous/high controlled motivation" (LA/HC), and "low autonomous/ low controlled motivation" (LA/LC). ${ }^{37}$ In a similar domain, Moran used cluster analysis to divide employees' motivation into five distinctive forms: such as (1) moderate levels of all motivation types, (2) high levels of all motivation types (eg, HA/HC profile), (3) low levels of autonomous motivation and moderate levels controlled motivation (4) high levels of intrinsic, identified, and introjected motivations and (5) moderate levels of all motivation types except for an introjection motivation. ${ }^{38}$ Despite the ubiquity and the great importance of clustering, many scholars have reported the drawbacks of employing cluster analysis. First, "the information collected through cluster sampling is heavily reliant on the skills of the researcher and that, if the data collection methods are subpar, then the data collected will not be as beneficial as it could be. Second, "cluster sampling only works well when people can be classified as units". Third, "the findings from cluster sampling only apply to those population groups". ${ }^{39-41}$ To overcome the weakness of previous studies, Grave employed LPA to investigate the motivational profiles of managers and revealed six distinct motivational profiles. ${ }^{42}$ For example, high autonomous motivational regulations and moderate levels of controlled motivations were investigated. Four other profiles were either very low, low, moderately low external motivation or high intrinsic, identified, and introjected motivations. The final profile comprised of moderately high levels of all four motives. ${ }^{42}$ Despite the robustness of the findings, the study has been plagued by the reliance on small samples. Joshua Howard overcomes this limitation by the inclusion of two large samples of employees from two different countries and reported four motivation profiles (eg, balanced motivation, amotivated, autonomously regulated and highly motivated) in the work domain that replicated across two large and heterogeneous samples of employees across multiple industries and job categories. ${ }^{43}$

Gabriel regards LPA as a person-centered approach. ${ }^{12}$ LPA helps researchers to know how variables conjoint to operate and how variables operate within people. LPA is based on the probability model. It allows for distinct subpopulations to be identified. LPA takes into consideration the most likely class membership and classification error rate. It can account for the error in profile classification by examining the links of the profiles with other variables. $^{44}$ Using a person-centered approach lets us understand how employees use different profiles of motivation to affect their work performance.

In the current research, we conducted 2 studies. In Study 1, we investigated whether there are different motivation profiles. In Study 2, we replicated the profile structure observed in Study 1 and investigated the implications of work motivation profiles for work performance.

\section{Study I: establishing the work motivation strategy}

Previous studies on intrinsic motivations, introjected regulations, identified regulations and extrinsic motivations draw on the separation perspective, and they consider motivations independently. Different motivations have been examined independently without considering the other motivations. According to the different combinations of four motivations in high or low levels, 16 potential work motivation combinations are observed. In accordance with SDT, motivations are varied in the degree to which it internalized. ${ }^{16}$ It is hard to diverge clearly from each other across different motivation profiles. Therefore, a person-centered approach can test whether there are different combinations of work motivations, which might provide a deeper way to understand work motivation.

\section{Method \\ Ethical statement}

The present study was reviewed and approved by the ethics review committees of the Donlinks School of Economics and Management. All subjects knew that they would be participating in a short survey and that they could withdraw from participation at any time. All participants provided written informed consent as per the Declaration of Helsinki.

\section{Participants and procedures}

Like many prior studies, ${ }^{45}$ the participants in Study 1 were from different companies in Beijing, Tianjin, Shandong, and Hebei who contacted via their HR managers randomly. We collected a total of 850 questionnaires. As a result, 842 participants provided valid responses for demographic characteristics and the work motivation scale. The response rate 
was $99.05 \%$. For participants included in the data analysis (46.1\% males and 53.9\% were females), their average age was $28.54,57.2 \%$ held a Bachelor's degree, and $36.1 \%$ held a Master's degree. Employees who agreed to complete the questionnaires were told that all the information were strictly confidential and only used for academic research. Participation was voluntary.

\section{Measures}

Work motivation. The questionnaire has 12 items and each dimension includes three items. Work motivation is measured through the general self-regulation scale. ${ }^{25}$ The question on the scale range from 1 (strongly disagree) to 7 (strongly agree). Some scholars have used the scale to conduct research on Chinese employees, indicating that the scale can effectively measure the motivation of Chinese employees. ${ }^{4}$ Cronbach's alpha coefficient for the scale was 0.925 . Fit indicators for confirmatory factor analysis (CFA) based on the data from Liseral 8.70 were as follows: $\mathrm{x} 2 / \mathrm{df}=3.81, \mathrm{CFI}=0.96$, IFI $=0.96$, NFI $=.89$, and RMSEA $=0.03$.

Control variables. We measured and controlled for the effects of "participants" age", "gender" ("1= male", and " 2 = female"), an "education level" ("1= associate degree" or below, " $2=$ Bachelor", and " $3=$ Master or above").

\section{Analytic procedure}

The LPA reveals heterogeneity in a sample. Using LPA can identify different profiles in which the individuals vary in performance on specific variables. ${ }^{46}$ In this article, they were external motivations, introjected regulations, identified regulations and intrinsic motivations. We used Mplus (Version 6) to conduct the LPA. According to Nylund, Asparouhov, and Muthén, we selected the best number of profiles in lines with the following fit indexes: ${ }^{18}$ "the Bayesian information criterion (BIC), the Akaike information criteria (AIC), the Vuong-Lo-Mendell-Rubin likelihood ratio test (VLMR), the Lo-Mendell-Rubin adjusted LRT test (LMR-A), the bootstrapped likelihood ratio test
(BLRT), and the entropy test". A better fit is observed when the $\mathrm{AIC}$ and $\mathrm{BIC}$ are lower and the $p$-value is significant. Entropy represents the degree that how many people are divided into the right types.

\section{Results}

Table 1 presents the correlations among variables, means, and standard deviations. We found that external motivations, introjected regulations, identified regulations, and intrinsic motivations were positively associated with each other though correlation analyses. Age was not related to external motivations, introjected regulations, identified regulations and intrinsic motivations $(p>0.05)$. There were no gender or age differences in these outcomes ( $p>0.05)$. Comparisons of participants who provided complete data with those who did not reveal any significant differences in age, gender proportion or education level (Table 2). Therefore, sampling bias should not be a concern for this study. Hence, the outcomes of the LPA were not influenced by age and gender.

The LPA estimated solutions use centered scores. Table 3 presents the fit indexes for the LPA in two different samples. The five-profile best fit the data according to the results. Although the BLRT of six-profiles was statistically significant, the entropy was low, and the VLMR and LMR-A were nonsignificant. The results of the fit indexes indicated that the five-profile solution provided the best fit.

Figure 1 contains the patterns of external motivations, introjected regulation, identified regulations and intrinsic motivations for each of five profiles. Profile 1 accounted for $18.2 \%$ of the sample and contained lower external motivations and introjected regulations, higher identified regulations, and intrinsic motivations. We label profile 1 as IM-dominant (intrinsic motivation-dominant). For the four motivations, they contain the highest intrinsic motivations. Profile 2 accounts for $7 \%$ of the sample and contains higher external motivations and lower introjected regulations and identifies regulations and intrinsic motivations. For the four motivations for profile 2, it contains the

Table I Correlations among variables, means, and standard deviations

\begin{tabular}{|l|l|l|l|l|l|l|}
\hline Variables & Means & SD & I & $\mathbf{2}$ & $\mathbf{3}$ \\
\hline I. External regulation & 3.65 & 1.27 & $\mathrm{I}$ & & & \\
2. Introjected regulation & 4.48 & 1.34 & $0.58^{* *}$ & $\mathrm{I}$ & \\
3. Identified regulation & 4.56 & 1.37 & $0.29^{* *}$ & $0.50^{* *}$ & $\mathrm{I}$ \\
4. Intrinsic motivation & 4.79 & 1.38 & $0.19^{* *}$ & $0.39^{* *}$ & $0.63^{* *}$ & $\mathrm{I}$ \\
\hline
\end{tabular}

Notes: Reliability coefficients are shown in bold along the diagonal of the table. $n=842 ; * * P<0.0$ I. 
Table 2 ANOVA results of gender, age and education level in Study I $(n=842)$

\begin{tabular}{|l|l|l|l|l|}
\hline & SS & df & mean & F \\
\hline Gender & 3.944 & 4 & 0.99 & $4.02^{* * *}$ \\
Age & 713.619 & 4 & $178.4 \mathrm{I}$ & $4.58^{* * *}$ \\
Education level & 18.979 & 4 & 4.75 & $11.01 * * *$ \\
\hline
\end{tabular}

Notes: $\mathrm{n}=842 ; * * * \mathrm{P}<0.005$.

Abbreviations: SS, sum-of-squares; df, degrees of freedom; MS, mean squares; F, F ratio.

lowest identified regulation. We label profile 2 as IMminor (intrinsic motivation-minor). Profile 3 consists of $23.9 \%$ of the sample and includes employees who have lower external motivations and higher introjected regulations, identified regulations and intrinsic motivations. For the four motivations for profile 3 , it contains the highest intrinsic motivations and lowest external motivations. We label profile 3 as low-midrange (low-midrange motivations). Profile 4 accounts for $32.5 \%$ of the sample and contains higher external motivations, introjected regulations and lower identified regulations and intrinsic motivations. We label profile 4 as high-midrange (high-midrange motivations). Profile 5 consists of $18.4 \%$ of the sample and contains the highest external motivations, introjected regulations, identified regulations, and intrinsic motivations compared to the other four types. We label profile 5 as dominant (dominant motivations).

Accordingly, we identify five different profiles of work motivations. We consider how to work differentiated motivations into the profiles. Then, we analyze the data using an analysis of variance (ANOVA). From Table 4, we obtained significant differences across different profiles in extrinsic motivations, introjected regulations, identified regulation and intrinsic motivations. Finally, we used multiple comparisons to identify between-group differences in variables.

The results of the profile mean comparisons across the five profiles are presented in Table 5. Significant differences are found in the extrinsic motivations between different profiles, except that IM-dominant, low-midrange, and IM-minor show no significant differences in the paired comparisons. Significant differences are observed between the groups in introjected motivations and identified

Table 3 Results of latent class analyses

\begin{tabular}{|l|l|l|l|l|l|l|}
\hline Number of groups & AIC & BIC & $\begin{array}{l}\text { VLMR } \\
\boldsymbol{p}\end{array}$ & $\begin{array}{l}\text { LMR-A } \\
\boldsymbol{P}\end{array}$ & $\begin{array}{l}\text { BLRT } \\
\boldsymbol{P}\end{array}$ \\
\hline 2 & 10735.57 & 10796.95 & 0.00 & 0.00 & 0.00 & 0.78 \\
3 & 10543.46 & 10628.45 & 0.03 & 0.03 & 0.00 & 0.70 \\
4 & 10402.68 & 10511.28 & 0.02 & 0.02 & 0.00 & 0.75 \\
5 & 10286.08 & 10418.28 & 0.00 & 0.00 & 0.00 & 0.77 \\
6 & 10234.01 & 10389.81 & 0.74 & 0.75 & 0.00 & 0.79 \\
\hline
\end{tabular}

Abbreviations: BIC, Bayesian information criteria; AIC, Akaike information criteria; VLMR, Vuong-Lo-Mendell-Rubin-likelihood ratio test; LMR-A, Lo-Mendell-Rubin adjusted LRT test; BLRT, Bootstrapped likelihood ratio test.

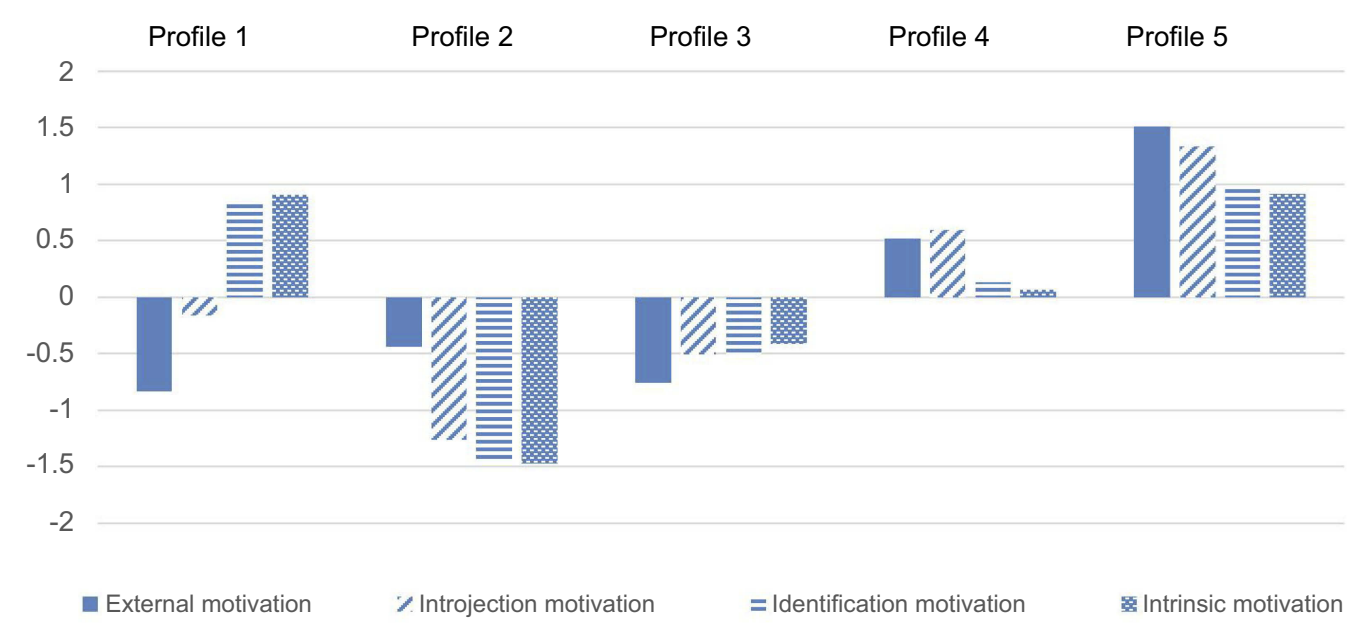

Figure I Profiles of work motivations from LPA (Study I). 
Table 4 ANOVA results of motivations in different profiles $(n=630)$

\begin{tabular}{|l|l|l|l|l|}
\hline Variables & SS & df & MS & F \\
\hline Extrinsic regulation & 761.47 & 4 & 190.37 & $268.02^{* * *}$ \\
Introjected regulation & 892.19 & 4 & 223.05 & $301.79 * * *$ \\
Identified regulation & 1252.61 & 4 & 313.15 & $804.99 * * *$ \\
Intrinsic motivation & 855.64 & 4 & 213.91 & $244.79 * * *$ \\
\hline
\end{tabular}

Notes: $\mathrm{n}=630 ; * * * \mathrm{p}<0.005$

Abbreviations: SS, sum-of-squares; df, degrees of freedom; MS, mean squares; F, F ratio.

motivations as well as in the intrinsic motivations between different profiles. Specifically, the IM-dominant and dominant are significantly higher than the other profiles, although they did not differ from each other.

\section{Study 2: replicating and expanding our understanding of the influence of work motivation on work performance}

Study 1 found five profiles that were different in the level (quantitative differences - dominant, high-midrange, and low-midrange) and shape (qualitative differences-IMminor and IM-dominant) of work motivation in the emerging market of China. Study 2 was designed to replicate the profile structure of work motivation in Study 1. Study 2 attempted to use different participants to verify the stability and universality of work motivation profiles. In addition, Study 2 expanded the outcomes by exploring the relationships between different work motivation profiles and different work performance. Based on Study 1, we believed that Study 2 could replicate Study 1. Thus, we proposed hypothesis 1 :
Hypothesis 1: The five identified latent profiles will vary quantitatively (Dominant, low-midrange, and high-midrange) and qualitatively (IM-dominant and IM-minor).

SDT showed that employee's motivation can influence their work performance. ${ }^{28,29}$ Cerasoli reported the positive effect of intrinsic motivation on "quality of work performance", that is to say, employee's task performance can be influenced by intrinsic motivation. ${ }^{7}$ External incentives reveal the message that an individual's competence is boosted. $^{32}$ Technical quantity and quality reflect a person's competence to accomplish task. ${ }^{47}$ Therefore, external regulation may foster task performance. ${ }^{52}$ Dedicated performance is related to intrinsic motivation because intrinsic motivation can impact motivational effort and persistence, ${ }^{48}$ and people who are motivated intrinsically will pay more intensity and effort in the activity. $^{7}$ Moreover, some researchers found that external rewards and incentives are necessary for persistence. ${ }^{49}$ Thus, we suggest that external regulations may also be related to dedicated performance. Employees are more willing to take part in the job of their colleagues when they are intrinsically motivated, which can increase their interpersonal performance. ${ }^{50}$ A significant positive relationship is observed between intrinsic motivations and creativity, ${ }^{51}$ and creativity is an instance of adaptive performance. Therefore, intrinsic motivations are related to adaptive performance. At the same time, some researchers believed that adaptive performance includes adjustment, innovation and so on. ${ }^{22}$ Adaptive performance can affect interpersonal behaviors, which are more likely to be related to identified regulations. ${ }^{4}$ Different profiles vary both quantitatively and qualitatively. ${ }^{36}$ A quantitative difference means that

Table 5 Multiple-comparison results of motivations $(n=630)$

\begin{tabular}{|c|c|c|c|c|c|}
\hline Profile & Profile & Extrinsic regulation & Introjected regulation & Identified regulation & Intrinsic motivation \\
\hline \multirow[t]{4}{*}{ Profile I } & Profile 2 & $-0.53 * * *$ & $1.58 * * *$ & $3.88 * * *$ & $3.35 * * *$ \\
\hline & Profile 3 & -0.15 & $0.59 * * *$ & $2.38^{* * *}$ & $2.14^{* * *}$ \\
\hline & Profile 4 & $-1.50 * *$ & $-0.77^{* * *}$ & $1.13 * * *$ & $1.44 * * *$ \\
\hline & Profile 5 & $-2.56 * * *$ & $-1.79 * * *$ & $-0.29 * * *$ & 0.03 \\
\hline \multirow[t]{3}{*}{ Profile 2} & Profile 3 & $0.38^{*}$ & $-0.99 * * *$ & $-1.49 * * *$ & $-1.21 * * *$ \\
\hline & Profile 4 & $-0.96 * * *$ & $-2.35 * * *$ & $-2.74 * * *$ & $-1.91 * * *$ \\
\hline & Profile 5 & $-2.03 * * *$ & $-3.37 * * *$ & $-4.17 * * *$ & $-3.32 * * *$ \\
\hline \multirow[t]{2}{*}{ Profile 3} & Profile 4 & $-1.35 * * *$ & $-1.37 * * *$ & $-1.24 * * *$ & $-0.70 * * *$ \\
\hline & Profile 5 & $-2.4 I^{* * *}$ & $-2.38 * * *$ & $-2.67 * * *$ & $-2.10 * * *$ \\
\hline Profile 4 & Profile 5 & $-1.06 * * *$ & $-1.01 * * *$ & $-1.43 * * *$ & $-\left.1.4\right|^{* * *}$ \\
\hline
\end{tabular}

Notes: The $p$-value represents a significant difference between different profiles in motivation. $n=630 ; * P<0.05, * * P<0.01, * * * P<0.005$. 
some profiles own high intrinsic motivations, identified regulations, introjected regulations and extrinsic motivations, and the other is low in intrinsic motivations, identified regulations, introjected regulations and extrinsic motivations. A qualitative difference means that some profiles have high intrinsic motivations, identified regulations and low deep introjected regulations and extrinsic motivations, whereas another profile performs moderate intrinsic motivations, identified regulations, introjected regulations and extrinsic motivations. Thus, we pursued the following relationships.

Hypothesis 2: Dominant, followed by high-midrange, will present higher (a) task performance, (b) interpersonal performance, (c) dedicated performance, and (d) adaptive performance compared with low-midrange.

Hypothesis 3: Dominant perform highest in (a) interpersonal performance, (b) adaptive performance, IM-dominant and low-midrange, and are lowest in IM-minor.

Hypothesis 4: Dominant and high-midrange perform highest in dedicated performance, followed by the IM-dominant and low-midrange and are lowest in IM-minor.

\section{Method}

\section{Participants and procedures}

The participants in Study 2 were from different companies in Beijing, Tianjin, Shandong, and Hebei. Their HR managers were contacted randomly. We collected a total of 650 questionnaires. A total of 630 participants provided valid responses for demographic characteristics and the work motivation scale. The corresponding supervisor assessed the employee's work performance. The response rate was $96.92 \%$. For participants included in the data analysis (56.7\% males and 53.9\%, 40.7\% were females), their average age was 28.7 (SD $=1.606), 41.2 \%$ held Bachelor's degrees, and 45.4\% held Master's degrees. Employees who agreed to complete the questionnaires were told that all the information would remain strictly confidential and would be used strictly for academic research. Participation was voluntary.

\section{Measures}

We carried out the same measures of work motivations as those in Study 1. The Cronbach's $\alpha$ was 0.925 . CFA was run to investigate whether the factor structure of this scale can be supported by the current data. The fit indicators based on the data from Liseral 8.70 were as follows: $\mathrm{x} 2 /$ df $=3.83$, CFI $=0$ 0.90, IFI $=0 \quad 0.93$, NFI $=0.87$, and RMSEA $=0.03$.

Work performance. The questionnaire has 29 items and four dimensions. ${ }^{2}$ Work performance was measured through the managers assessed their subordinate's performance. The questions were provided using a 5-point Likert-type scale. The scale used Chinese subjects as samples to explore structure and measurement items of the scale. $^{2}$ In addition, it was cited 475 times on the China National Knowledge Infrastructure. Many scholars have used the scale to conduct research on Chinese employees. ${ }^{4}$ Therefore, the scale can effectively measure the work performance of Chinese employees. The Cronbach's $\alpha$ was 0.950 . CFA was run to determine whether the factor structure of this scale can be supported by the current data. The fit indicators based on the data from Liseral 8.70 were as follows: $\mathrm{x} 2 / \mathrm{df}=2.67, \mathrm{CFI}=0.91$, IFI $=0.92$, NFI $=0.88$, and $\mathrm{RMSEA}=0.03$.

Control variables. We measured and controlled for the effects of "participants" age", "gender" ("1=male", and " $2=$ female"), an "education level" ("1=Associate's degree" or below, " $2=$ Bachelor's degree", and " $3=$ Master's degree or above").

\section{Results}

The descriptive statistics and correlations among work motivations (external motivations, introjected regulations, identified regulations and intrinsic motivations) and work performance (task performance, interpersonal performance, adaptive performance, and dedicated performance) appear in Table 6. The results show that different motivations were positively related to different work performances. The results of the correlation analysis generally supported the positive effects of work motivations on work performances. Comparisons of participants who provided complete data with those who did not reveal any significant differences in age, gender proportion or education level (Table 7). Therefore, sampling bias should not be a concern for this study.

Table 8 shows the results of LPAs. According to the criteria from Study 1, the five-profile was still the best solution and showed the low AIC, BIC statistics, significant LMR and BLRT statistics, and large entropy. Sixsolution had lower AIC, BIC, and larger entropy, but its LMR and BLRT statistics were nonsignificant. Notably, these statistics have been believed the most important in choosing the correct solution. ${ }^{44}$ 
Table 6 Correlations among variables, means, and standard deviations

\begin{tabular}{|c|c|c|c|c|c|c|c|c|c|c|}
\hline Variables & Means & SD & $\mathbf{I}$ & 2 & 3 & 4 & 5 & 6 & 7 & 8 \\
\hline I Extrinsic regulation & 3.69 & 1.29 & I & & & & & & & \\
\hline 2 Introjected regulation & 4.57 & 1.28 & $0.51 * *$ & I & & & & & & \\
\hline 3 Identified regulation & 4.66 & 1.35 & $0.34 * *$ & $0.59 * *$ & I & & & & & \\
\hline 4 Intrinsic motivation & 4.73 & 1.35 & $0.20 * *$ & $0.42 * *$ & $0.67 * *$ & I & & & & \\
\hline 5 Task performance & 3.40 & 0.70 & $0.22 * *$ & $0.20 * *$ & $0.12 * *$ & $0.11^{* *}$ & I & & & \\
\hline 6 Dedicative motivation & 3.83 & 0.63 & $0.13^{* *}$ & $0.15 * *$ & $0.17 * *$ & $0.13 * *$ & $0.63 * *$ & I & & \\
\hline 7 Interpersonal motivation & 3.58 & 0.69 & $0.17 * *$ & $0.14 * *$ & $0.13 * *$ & $0.13 * *$ & $0.70 * *$ & $0.69 * *$ & I & \\
\hline 8 Adaptive motivation & 3.56 & 0.70 & $0.15^{* *}$ & $0.18 * *$ & $0.26 * *$ & $0.18^{* *}$ & $0.60 * *$ & $0.59 * *$ & $0.5 I^{* *}$ & I \\
\hline
\end{tabular}

Notes: Reliability coefficients are shown in bold along the diagonal of the table. $n=630 ; * * P<0.01$. Two-tailed tests.

Table 7 ANOVA results of gender, age and education level in Study $2(n=630)$

\begin{tabular}{|l|l|l|l|l|}
\hline & SS & df & mean & F \\
\hline Gender & 2.153 & 4 & 0.538 & 2.178 \\
Age & 816.156 & 4 & 204.039 & 4.927 \\
Education level & 3.722 & 4 & 0.931 & 2.334 \\
\hline
\end{tabular}

Note: $n=630$.

Abbreviations: SS, sum-of-squares; df, degrees of freedom; MS, mean squares; F, F ratio.

As shown Figure 2, the five profiles were similar to the profiles in Study 1. Profile 4 (high-midrange) (M external motivation $=4.1170, \mathrm{M}$ introjected regulation $=4.9618, \mathrm{M}$ identified regulation $=4.6246$, and $\mathrm{M}$ intrinsic motivation $=4.4680)$ had the majority of the participants $(31.42 \%)$, followed by profile 3 (low-midrange) (24.28\%, M external motivation $=2.7712, \mathrm{M}$ introjected regulation $=3.5948, \mathrm{M}$ identified regulation $=3.3791$, and $\mathrm{M}$ intrinsic motivation $=3.7712)$, profile 5 (dominant) $(20.95 \%$, M external motivation $=5.1798, \mathrm{M}$ introjected regulation $=5.9747, \mathrm{M}$ identified regulation $=6.0556$, and $\mathrm{M}$ intrinsic motivation $=5.8753)$ and profile 1 (IM-dominant) $(17.46 \%, \mathrm{M}$ external motivation $=2.6202, \mathrm{M}$ introjected regulation $=4.1846, \mathrm{M}$ identified regulation $=5.7582$, and $\mathrm{M}$ intrinsic motivation $=5.9082$ ). The smallest profile was profile 2 (IM-minor)
(5.87\%, M external motivation $=3.1532$, $\mathrm{M}$ introjected regulation $=2.6-81 \mathrm{M}$ identified regulation $=1.8829$, and $\mathrm{M}$ intrinsic motivation $=2.5595$ ). The general structure was replicated, thus supporting hypothesis 1 that dominant, IM-dominant, high-midrange, low-midrange, and IM-minor would be identified.

Once the profiles of motivation were identified, they were compared on measures of job performance. The mean differences are presented in Figure 3.

An ANOVA was performed to compare profiles (Table 9). The five identified profiles differed significantly on work performance, thus indicating that profiles varied on several outcome measures.

From Table 10, we obtained significant differences across different profiles in different motivations. Then, we used multiple comparisons to identify between-profile differences in variables.

Task performance was highest in the dominant profile followed by the high-midrange, whereas the lowest was in the low-midrange, IM-dominant, and IM-minor. Please see Figure 3 for details. Employees in the profiles of IM-minor, low-midrange, and IM-dominant did significantly vary in task performance; however, they presented significantly lower levels than employees with the dominant and highmidrange profiles, with the former being significantly greater

Table 8 Results of latent class analyses

\begin{tabular}{|l|l|l|l|l|l|l|}
\hline Number of groups & AIC & BIC & $\begin{array}{l}\text { VLMR } \\
\boldsymbol{p} \text {-value }\end{array}$ & $\begin{array}{l}\text { LMR-A } \\
\boldsymbol{p} \text {-value }\end{array}$ & $\begin{array}{l}\text { BLRT } \\
\boldsymbol{p} \text {-value }\end{array}$ & $\begin{array}{l}\text { Entropy } \\
2\end{array}$ \\
3 & 8106.41 & 8164.18 & 0.01 & 0.01 & 0.00 & 0.79 \\
4 & 7945.51 & 8025.51 & 0.00 & 0.00 & 0.00 & 0.88 \\
5 & 7829.60 & 7931.82 & 0.01 & 0.02 & 0.00 & 0.78 \\
6 & 7696.01 & 7820.45 & 0.00 & 0.00 & 0.00 & 0.79 \\
\hline
\end{tabular}

Abbreviations: BIC, Bayesian information criteria; AIC, Akaike information criteria; VLMR, Vuong-LoMendell-Rubin-likelihood ratio test; LMR-A, Lo-Mendell-Rubin adjusted LRT test; BLRT, Bootstrapped likelihood ratio test. 


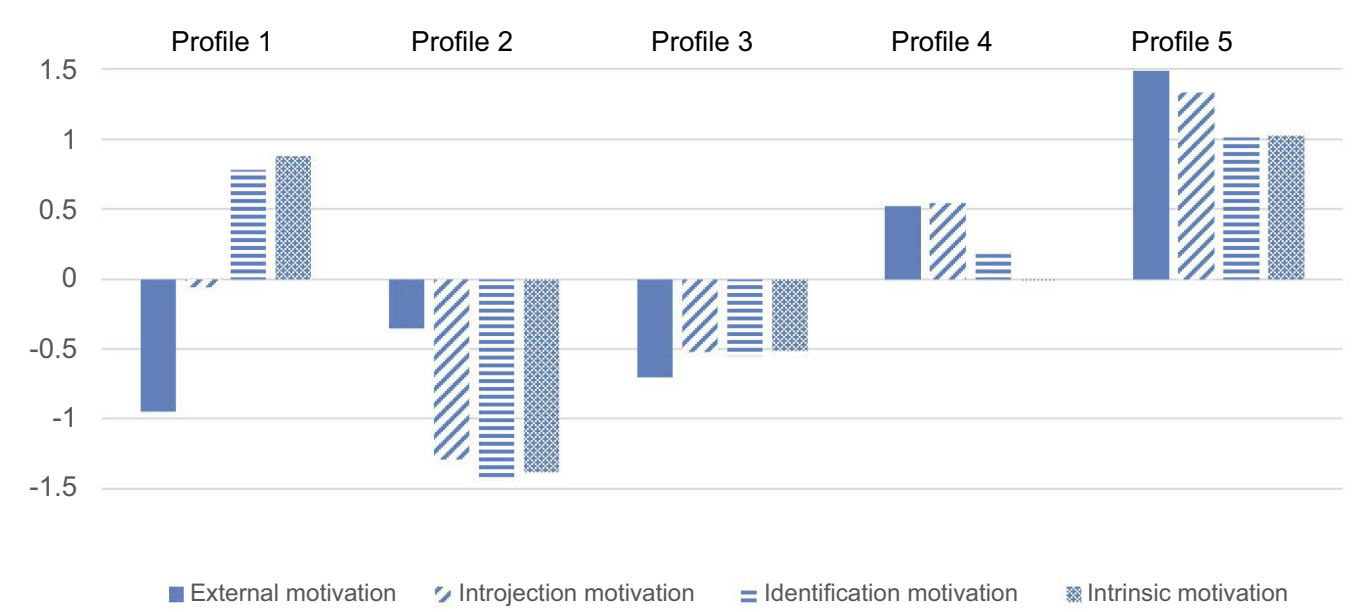

Figure 2 Groups of work motivations from LPA (Study 2).

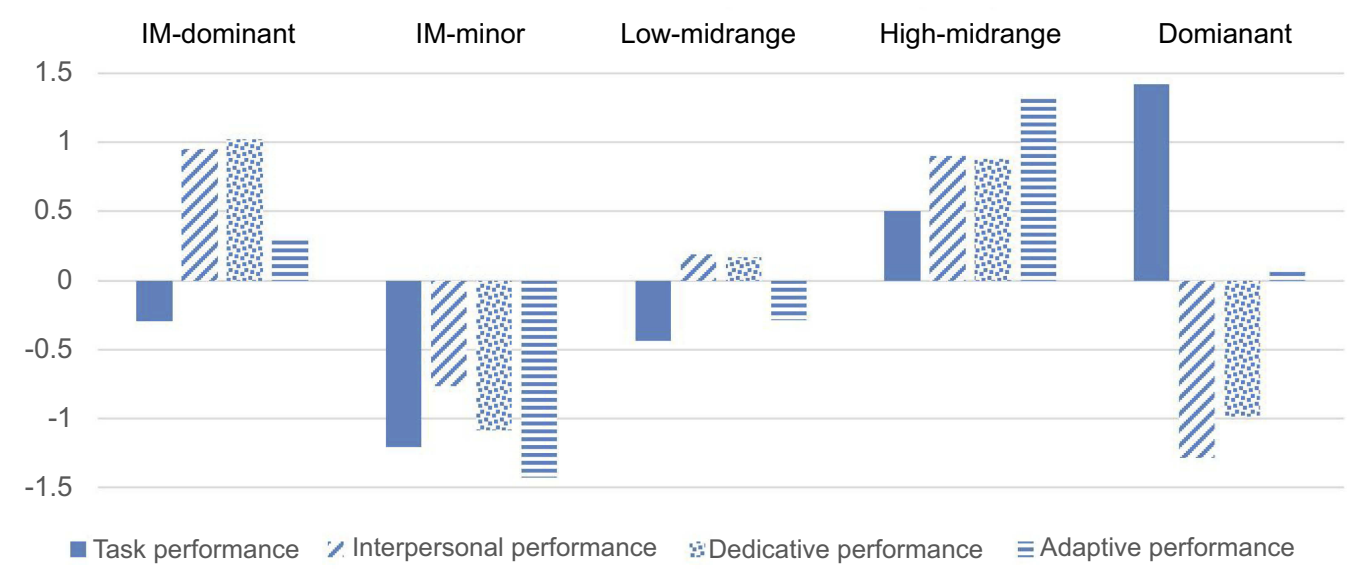

Figure 3 Mean task performance, dedicated performance, interpersonal performance.

Table 9 ANOVA results of motivations in different profiles

\begin{tabular}{|l|l|l|l|l|}
\hline Variables & SS & df & MS & F \\
\hline Task performance & 16.03 & 4 & 4.01 & $8.53^{* * *}$ \\
Interpersonal performance & 11.72 & 4 & 2.92 & $6.28^{* * *}$ \\
Dedicative performance & 12.40 & 4 & 3.10 & $8.21^{* * *}$ \\
Adaptive performance & 16.71 & 4 & 4.18 & $8.66 * * *$ \\
\hline
\end{tabular}

Notes: $\mathrm{n}=630 ; * * * \mathrm{p}<0.005$.

than the latter. The interpersonal performance was highest in the work motivation profiles in the dominant, followed by the IM-dominant, high-midrange, low-midrange, and IM-minor. Please see Figure 3 for details. Employees in the dominant and IM-dominant and high-midrange profiles did not show significant differences in interpersonal performance; however, they all hold significantly higher levels than employees with the low-midrange and IM-minor profiles. The dominant profile presented the highest dedicated performance, followed by the IM-dominant, high-midrange, low-midrange, and IM-minor. Figure 3 verified that employees reporting as dominant performed better than did employees with IMdominant, high-midrange, low-midrange, and IM-minor. The dominant and high-midrange profiles presented the highest adaptive performance, followed by IM-dominant, lowmidrange, and IM-minor, as indicated in Figure 3. Employees with dominant and IM-dominant profiles did not show significant differences in interpersonal performance; however, they presented significantly higher levels than did employees in the high-midrange, low-midrange, and IM-minor profiles. According to the results, hypothesis 2 and hypothesis 3 were supported, but hypothesis 4 was not absolutely supported.

\section{Discussion}

The purpose of this study was to identify the structures and functions of work motivation profiles by using a personcentered approach (LPA) ${ }^{14}$ under the framework of SDT and 
Table 10 Multiple-comparison results of work performance

\begin{tabular}{|l|l|l|l|l|l|}
\hline Profile & Profile & Task performance & Interpersonal performance & Dedicative performance & Adaptive performance \\
\hline Profile 1 & Profile 2 & 0.21 & $0.38^{* *}$ & $0.39^{* *}$ & $0.57^{* * *}$ \\
& Profile 3 & 0.03 & $0.17^{*}$ & $0.16^{*}$ & $0.19^{*}$ \\
& Profile 4 & $-0.18^{*}$ & 0.01 & $0.03^{*}$ & $0.07^{*}$ \\
& Profile 5 & $-0.34^{* * *}$ & -0.14 & $-0.16^{*}$ & -0.12 \\
\hline Profile 2 & Profile 3 & -0.18 & -0.21 & $-0.23^{*}$ & $-0.37^{* *}$ \\
& Profile 4 & $-0.39^{* *}$ & $-0.04^{* *}$ & $-0.37^{* *}$ & $-0.49^{* * *}$ \\
& Profile 5 & $-0.55^{* * *}$ & $-0.53^{* * *}$ & $-0.56^{* *}$ & $-0.69^{* * *}$ \\
\hline Profile 3 & Profile 4 & $-0.22^{* *}$ & $-0.16^{*}$ & $-0.13^{*}$ & $-0.12^{* *}$ \\
& Profile 5 & $-0.37^{* *}$ & $-0.31^{* * *}$ & $-0.32^{* * *}$ & $-0.31^{* * *}$ \\
\hline Profile 4 & Profile 5 & $-0.15^{*}$ & $-0.15^{*}$ & $-0.19^{* *}$ & -0.19 \\
\hline
\end{tabular}

Notes: The $p$-value represents a significant difference between different profiles in motivations. $\mathrm{n}=630 ; * p<0.05, * * p<0.01, * * * p<0.005$.

to explore the relationships between work motivations and different work performances in the workplace. Generally, the results of the two studies found five profiles that were different in the level (quantitative differences-dominant, high-midrange, and low-midrange) and shape (qualitative differences-IM-minor and IM-dominant) of the profile indicators. Joshua Howard employed LPA to divide the employees' motivation into four different types: amotivated, moderately autonomous, highly motivated and balanced. ${ }^{43}$ In our research, we found dominant is similar to highly motivated in Joshua's research. Their different motivations were all high level. IM-dominant in our research is similar to moderately autonomous. They both owned above-average levels of identified regulation and internal motivation, below-average levels of introjected motivation and low level of external regulation. Likewise, IM-minor in our research is somehow similar to amotivated and balanced. Prior research by Joshua Howard presented a little high in external motivation and low in introjected motivation, identified motivation, and internal motivation. It was interesting that our data revealed low-midrange which profiles characterized moderate below-average levels of all motivations and high-midrange which profiles characterized moderate above-average levels of all motivations. In Study1 low-midrange and high-midrange separately consisted of $23.9 \%$ and $32.5 \%$ of the sample. In Study 2 lowmidrange and high-midrange separately accounted for $31.42 \%$ and $24.28 \%$ of the whole samples. Obviously, these two types of employee's work motivation occupied more than $50 \%$ of the samples in both Study 1 and Study 2 . In Chinese culture, "Zhong Yong" thinking prolonged for a long time. They used multiple perspectives to think about one phenomenon in different ways. After thinking about all different views in detail, people will make the choices that consider themselves and the overall situation at the same time. ${ }^{53,54}$ So their behaviors are motivated by moderately different motivations at the same time.

These different profiles had a different relationship with four work performance. Dominant exhibited higher task performance, interpersonal performance, adaptive performance, and dedicated performance when compared with all other profiles (although not significantly different from IM-dominant on interpersonal performance and adaptive performance). High-midrange exhibited higher task performance and interpersonal performance. Lowmidrange exhibited lower task performance, interpersonal performance, adaptive performance, and dedicated performance. IM-minor exhibited the lowest interpersonal performance, adaptive performance, and dedicated performance when compared with all profiles, but their task performance was a little better. IM-dominant exhibited higher adaptive performance and dedicated performance closely following the dominant and its higher interpersonal performance closely followed the high-midrange, but their task performance was worse.

The major theoretical contribution of this research is that we used LPA to demonstrate five different subpopulations that can exhibit different combinations of work motivations, which contributed greatly to previous studies on work motivation in terms of the perspectives of personcentric paradigms and separation. The contribution of this work is that it can provide an explanation of the different relationships between work motivations and work performances. In particular, three profiles (dominant, high- 
midrange, and low-midrange) provide evidence to show that different motivations can coexist within individuals at comparable levels, and two profiles (IM-dominant and IMminor) provide evidence.

Second, our results show that identified regulation is important in predicting work performance. Identified regulations can promote and protect intrinsic motivations rather than diminish them. Identified regulations were more important in predicting work performance. ${ }^{4}$ Compared to employees with low identified regulations and intrinsic motivations and high introjected regulations and extrinsic motivations (high-midrange) employees with high identified regulations and intrinsic motivations and low introjected regulations and extrinsic motivations (IMdominant) have significantly higher interpersonal performance, dedicative performance, and adaptive performance.

Third, we advance the SDT research through this work. This study explored the relations between different motivation profiles and work performance. The usual argument is that intrinsic motivation is the most potent predictor. ${ }^{10}$ Compared with employees with low extrinsic motivations and high intrinsic motivations (IM-dominant), employees with high intrinsic motivations and low extrinsic motivations (IM-dominant) have good task performance. In strategies of combinations of different motivations, employees' work performance cannot be determined by one motivation independently. This research believes that employees are a complex system and that individuals experience different levels of different work motivations. Thus, this research extends previous research about work motivation.

\section{Practical implications}

First, in practice, managers can use different management approaches for different work motivation strategies. For example, managers can stimulate the external motivation level of IM-dominant through management intervention, which can improve an employee's task performance. IMminor, high-midrange, low-midrange can be motivated through training, in order to promote their work performance. Managers can provide more autonomy support for dominant, which can assistant employees obtain better performance.

Second, managers can help the organization to optimize its human resources components by identifying work motivation profiles. Managers can help the organization save human resource costs by identifying work motivation profiles. For example, when recruiting new members, managers should try their best to choose the employees whose work motivation strategy fits their organization. Managers can also let go of employees that might contribute little to the organization.

Third, managers should consider working conditions or other ways to buffer and reduce the impact of work motivation on work performance. For example, coordination among employees who have different work motivation profiles can complement team performance. The combination of employees' different motivation strategies may promote team performance.

\section{Implications for future research}

First, future research can explore the antecedent of work motivation profiles. Researchers can study whether personality traits, work environment, the social network can impact employees use different work motivations.

Second, future research can detect the work behavior of different work motivation profiles, for example, work passion, pro-social behavior, green behavior. The study used Wen's work performance scales to assess Chinese employees' work performance, which was performed in a Chinese organizational environment. We can also examine whether countries with different cultures will show similar findings. Future research in different countries is needed to further understand the different combinations of work motivations in those cultures.

Third, our participants did not include all types of occupations, such as nurses or soldiers. We should confirm whether a similar combination of work motivations can be extended to other occupations. Future work may consider testing multiple profiles in different occupations.

Fourth, we studied only general work motivations; thus, dynamic variations were not observed. A meaningful direction would be to test the change in motivation over time. Moreover, other person-centered techniques can be used to assess changes over time, such as latent transition analysis, ${ }^{55}$ and they could be implemented to show if and when people utilize different strategies over time.

\section{Acknowledgment}

The article is supported by the Natural Science Foundation of China (Grant No. 71771022), Basic research funding project of the University of Science and Technology Beijing (Grant No. FRF-BR-18-001B).

\section{Disclosure}

The authors report no conflicts of interest related to this work. 


\section{References}

1. Campbell JP. Modeling the performance prediction problem in industrial and organizational psychology. In: Dunnette M, Hough L, editors. Handbook of Industrial \& Organizational Psychology. Consulting Psychologists. Palo Alto; 1990.Vol.1. 687-732.

2. Wen Z. Four-factor model of job performance. J Capital Normal Univ. 2005;(5):105-111.

3. Pinder CC. Work Motivation in Organizational Behavior. Psychology Press. NJ:Prentice-Hall;2014.

4. Zhang J, Zhang Y, Song Y, Gong Z. The different relations of extrinsic, introjected, identified regulation and intrinsic motivation on employees' performance: empirical studies following self-determination theory. Manage Decis. 2016;54(10):2393-2412. doi:10.1108/MD-01-20160007

5. Koestner R, Losier GF. Distinguishing three ways of being highly motivated a closer look at introjection, identification, and intrinsic motivation. In: Deci EL, Ryan RM, editors. Handbook of Self-determination Theory Research. New York, NY: University of Rochester Press; 2002:101-121.

6. Rogstadius J, Kostakos V, Kittur A, Smus B, Laredo J, Vukovic M. An assessment of intrinsic and extrinsic motivation on task performance in crowdsourcing markets. International Conference on Weblogs and Social Media; July; 2011; Barcelona, Catalonia, Spain: DBLP.

7. Cerasoli CP, Nicklin JM, Ford MT. Intrinsic motivation and extrinsic incentives jointly predict performance: a 40-year meta-analysis. Psychol Bull. 2014;140(4):980. doi:10.1037/a0035661

8. Vansteenkiste M, Lens W, Deci EL. Intrinsic versus extrinsic goal contents in self-determination theory: another look at the quality of academic motivation. Educ Psychol. 2006;41(1):19-31. doi:10.1207/ s15326985ep4101_4

9. Mekler ED, Brühlmann F, Tuch AN, Opwis K. Towards understanding the effects of individual gamification elements on intrinsic motivation and performance. Comput Human Behav. 2017;1(71):525534. doi:10.1016/j.chb.2015.08.048

10. Deci EL, Ryan RM. The "what" and "why" of goal pursuits: human needs and the self-determination of behavior. Psychol Inq. 2000;11 (4):227-268. doi:10.1207/S15327965PLI1104_01

11. Gagné M, Deci EL. Self-determination theory and work motivation. $J$ Organ Behav. 2005;26(4):331-362. doi:10.1002/job.v26:4

12. Gagné M, Forest J, Vansteenkiste $M$, et al. The multidimensional work motivation scale: validation evidence in seven languages and nine countries. Eur J Work Organizational Psychol. 2015;24(2):178196. doi:10.1080/1359432X.2013.877892

13. Griner LA, Smith CA. Contributions of motivational orientation to appraisal and emotion. Pers Soc Psychol Bull. 2000;26(6):727-740. doi: $10.1177 / 0146167200268007$

14. Mo W, Hanges PJ. Latent class procedures: applications to organizational research. Organizational Res Methods. 2011;14(1):24-31. doi:10.1177/1094428110383988

15. Kanfer R, Chen G, \& Pritchard, R. D. (Eds.). Work Motivation: Past, Present and Future. New York, NY: Routledge; 2012.

16. Deci EL, Ryan RM. The general causality orientations scale: selfdetermination in personality. $J$ Res Pers. 1985;19(2):109-134. doi:10.1016/0092-6566(85)90023-6

17. Gilal FG, Zhang J, Paul J. The role of self-determination theory in marketing science: an integrative review and agenda for research. Eur Manage J. 2019;37(1):29-44. doi:10.1016/j.emj.2018.10.004

18. Gagné M, Forest J, Gilbert, M. H. , Aube, C. , \& Malorni, A. The motivation at work scale: validation evidence in two languages. Educ Psychol Meas. 2010;70(4):628-646. doi:10.1177/0013164409355698

19. Koestner R, Losier GF. Distinguishing Three Ways of Being Highly Motivated: A Closer Look at Introjection, Identification, and Intrinsic Motivation. In E. L. Deci, \& R. M. Ryan (Eds.), Handbook of selfdetermination research. Rochester, NY: University of Rochester Press.2002.101-121
20. Gagné M, Deci EL. Self-determination theory and work motivation. $J$ Organ Behav. 2005;26(4):331-362. doi:10.1002/job.v26:4

21. Koopmans L, Bernaards CM, Hildebrandt, V. H. , Vet, H. C. D. , \& Beek, A. J. V. D. Measuring individual work performance: identifying and selecting indicators. Work. 2014;48(2):229-238. doi:10.3233/ WOR-131659

22. Borman WC, Motowidlo SM. Expanding the criterion domain to include elements of contextual performance. In: Personnel Selection in Organizations. San Francisco: Jossey-Bass.Borman and associates (eds.); 1993:71.

23. Pulakos ED, Arad S, Donovan MA, Plamondon KE. Adaptability in the workplace: development of a taxonomy of adaptive performance. $J$ Appl Psychol. 2002;85(4):612-624. doi:10.1037/0021-9010.85.4.612

24. Griffin MA, Neal A, Parker SK. A new model of work role performance: positive behavior in uncertain and interdependent contexts. Acad Manage J. 2007;50(2):327-347. doi:10.5465/amj.2007.24634438

25. Rotundo M, Sackett PR. The relative importance of task, citizenship, and counterproductive performance to global ratings of job performance: a policy-capturing approach. J Appl Psychol. 2002;87(1):66. doi:10.1037/0021-9010.87.1.66

26. Dalal RS. A meta-analysis of the relationship between organizational citizenship behavior and counterproductive work behavior. $J \mathrm{Appl}$ Psychol. 2005;90(6):1241. doi:10.1037/0021-9010.90.6.1241

27. Allworth E, Hesketh B. Construct-oriented biodata: capturing change-related and contextually relevant future performance. Int $J$ Sel Assess. 1999;7(2):97. doi:10.1111/1468-2389.00110

28. Burton KD, Lydon JE, D"Alessandro, D. U. , \& Koestner, R. . The differential effects of intrinsic and identified motivation on well-being and performance: prospective, experimental, and implicit approaches to self-determination theory. J Pers Soc Psychol. 2006;91(4):750. doi:10.1037/0022-3514.91.4.750

29. Deci EL, Connell JP, \& Ryan, R. M. Self-determination in a work organization. J Appl Psychol. 1989;74(4):580. doi:10.1037/00219010.74.4.580

30. Dysvik A, Kuvaas B. Intrinsic and extrinsic motivation as predictors of work effort: the moderating role of achievement goals. Br J Social Psychol. 2013;52(3):412-430. doi:10.1111/j.2044-8309.2011.02090.x

31. Cerasoli CP, Nicklin JM, \& Ford, M.T. Intrinsic motivation and extrinsic incentives jointly predict performance: a 40-year meta-analysis. Psychol Bull. 2014;140(4):980. doi:10.1037/a0035661

32. Deci EL, Koestner R, \& Ryan, RM. A meta-analytic review of experiments examining the effects of extrinsic rewards on intrinsic motivation. Psychol Bull. 1999;125(6):627. doi:10.1037/00332909.125.6.627

33. Shaw JD, Gupta N. Let the evidence speak again! Financial incentives are more effective than we thought. Human Res Manage J. 2015;25(3):281-293. doi:10.1111/hrmj.2015.25.issue-3

34. Shin SJ, Zhou J. Transformational leadership, conservation, and creativity: evidence from Korea. Acad Manage J. 2003;46(6):703714. doi: $10.5465 / 30040662$

35. Morgeson FP, Hofmann DA. The structure and function of collective constructs: implications for multilevel research and theory development. Acad Manage Rev. 1999;24(2):249-265. doi:10.5465/ amr.1999.1893935

36. Marsh HW, Lüdtke O, Trautwein, U. , \& Morin, A. J. S. Classical latent profile analysis of academic self-concept dimensions: synergy of person-and variable-centered approaches to theoretical models of self-concept. Struct Equation Model. 2009;16(2):191-225. doi:10.1080/ 10705510902751010

37. Broeck AVD, Lens W, De Witte, H. , \& Van Coillie, H. Unraveling the importance of the quantity and the quality of workers' motivation for well-being: a person-centered perspective. J Vocat Behav. 2013;82 (1):69-78. doi:10.1016/j.jvb.2012.11.005

38. Moran CM, Diefendorff JM, Kim, TY. , \& Liu, ZQ. A profile approach to self-determination theory motivations at work. $J$ Vocat Behav. 2012;81(3):354-363. doi:10.1016/j.jvb.2012.09.002 
39. Meyer JP, Morin AJS. A person-centered approach to commitment research: theory, research, and methodology. J Organ Behav. 2016;37 (4):n/a-n/a. doi:10.1002/job.2085

40. Morin AJ, Maã Ano C, Marsh, HW., Janosz, M., \& Nagengast, B. The longitudinal interplay of adolescents' self-esteem and body image: a conditional autoregressive latent trajectory analysis. Multivariate Behav Res. 2011;46(2):157-201. doi:10.1080/ 00273171.2010 .546731

41. Vermunt JK, Magidson J. Latent Class Cluster Analyses. Hagenaars \& A. L. McCutcheon (Eds.), Applied latent class analysis. Cambridge, MA: Cambridge University Press. 2002.89-106.

42. Graves LM, Cullen KL, Lester HF, Ruderman MN, Gentry WA. Managerial motivational profiles: composition, antecedents, and consequences. J Vocat Behav. 2015;87(87):32-42. doi:10.1016/j. jvb.2014.12.002

43. Howard J, Gagné M, Morin AJ, Van den Broeck A. Motivation profiles at work: a self-determination theory approach. J Vocat Behav. 2016;95-96:74-89. doi:10.1016/j.jvb.2016.07.004

44. Gabriel AS, Daniels MA, Diefendorff JM, et al. Emotional labor actors: a latent profile analysis of emotional labor strategies.[J]. $J$ Appl Psychol. 2015;100(3):863-879. doi:10.1037/a0037408

45. Gilal FG, Zhang J, Gilal NG, Gilal RG. Association between a parent's brand passion and a child's brand passion: a moderated moderated-mediation model. Psychol Res Behav Manag. 2018;11:91-102. doi:10.2147/PRBM.S161755

46. Nylund KL, Asparouhov T, Muthén BO. Deciding on the number of classes in latent class analysis and growth mixture modeling: a Monte Carlo simulation study. Struct Equation Model A Multi J. 2007;14 (4):535-569. doi:10.1080/10705510701575396

47. de Jesus SN, Rus CL, Lens W, Imaginário S. Intrinsic motivation and creativity related to product: a meta-analysis of the studies published between 1990-2010. Creat Res J. 2013;25(1):80-84. doi:10.1080/ 10400419.2013 .752235
48. Deci EL. The effects of contingent and noncontingent rewards and controls on intrinsic motivation. Organ Behav Hum Perform. 1972;8 (2):217-229. doi:10.1016/0030-5073(72)90047-5

49. Amabile TM. Motivational synergy: toward new conceptualizations of intrinsic and extrinsic motivation in the workplace. Human Resour Manage Rev. 1993;3(3):185-201. doi:10.1016/ 1053-4822(93)90012-S

50. Guay F, Vallerand RJ, Blanchard C. On the assessment of situational intrinsic and extrinsic motivation: the Situational Motivation Scale (SIMS). Motiv Emot. 2000;24(3):175-213. doi:10.1023/ A: 1005614228250

51. Simons J, Dewitte S, Lens W. The role of different types of instrumentality in motivation, study strategies, and performance: know why you learn, so you'll know what you learn! $\mathrm{Br} J$ Educ Psychol. 2004;74(3):343-360. doi:10.1348/00070990415 52314

52. Steers RM, Mowday RT, Shapiro DL. The future of work motivation theory. Acad Manage Rev. 2004;29(3):379-387.

53. He C, Gu J, Wu W. Social media use in the career development of graduate students: the mediating role of internship effectiveness and the moderating role of Zhongyong. Higher Educ. 2017;74(6):10331051. doi:10.1007/s10734-016-0107-8

54. Yang X, Zhang $\mathrm{P}$, Zhao J. Confucian culture still matters: the benefits of Zhongyong thinking (Doctrine of the mean) for mental health. J Cross-cultual Psychol. 2016;47(8):1097-1113. doi:10.1177/ 0022022116658260

55. Wang M, Chan D. Mixture latent Markov modeling: identifying and predicting unobserved heterogeneity in longitudinal qualitative status change. Organizational Res Methods. 2011;14(3):411-431. doi: $10.1177 / 1094428109357107$
Psychology Research and Behavior Management

\section{Publish your work in this journal}

Psychology Research and Behavior Management is an international, peer-reviewed, open access journal focusing on the science of psychology and its application in behavior management to develop improved outcomes in the clinical, educational, sports and business arenas. Specific topics covered in the journal include: Neuroscience, memory and decision making; Behavior modification and management; Clinical applications; Business and sports performance management; Social and developmental studies; Animal studies. The manuscript management system is completely online and includes a very quick and fair peer-review system, which is all easy to use. Visit http://www. dovepress.com/testimonials.php to read real quotes from published authors. 